\title{
POWER SYSTEM STABILISATION BASED ON GA-ANFIS IN GENERATORS
}

\author{
B.ChristyJuliet $^{1}$, D.Vinothini ${ }^{2}$, S.Vidhyashree $^{3}$ \\ ${ }^{I}$ M.E Power System Engineering, Kalaignar Karunanidhi Institute of Technology, Coimbatore-641 402 \\ ${ }^{2}$ M.E Power System Engineering, Kalaignar Karunanidhi Institute of Technology, Coimbatore-641 402 \\ ${ }^{3}$ M.E Power System Engineering, Kalaignar Karunanidhi Institute of Technology, Coimbatore-641 402
}

\begin{abstract}
At Mettur Thermal Power Station, 840 MW of Electricity is produced in 4 units, each of 210 MW capacity, at 15.75 KV, 9000 A. This power is fed into the grid by stepping up with generator transformer at $230 \mathrm{KV}$. The generator terminal voltage and the reactive load flow are controlled by STATIC EXCITATION SYSTEM. One of its main components is AVR. The major function of the AUR is to hold a constant generator output voltage (terminal voltage, Vt) when the VAR loads of the grid varies at the leading and lagging power factors. This is achieved by varying the excitation voltage (Ve) and excitation current (Ie). AVR gives the control signals to the Thyristor blocks which in turn control the excitation voltage to maintain the constant terminal voltage of the generator. This paper work comprises of design of Power System Stabilizers (PSS) with Adaptive Neuro Fuzzy Inference System (ANFIS).The AVR function is carried out by ANFIS in order to damp the low frequency power system oscillations and to provide faster response thereby improving the unit dynamic performance
\end{abstract}

Keywords: AVR, power system stabilizer, GA-ANFIS.

\section{INTRODUCTION}

Electric Power is important commodity in modern world and the total of a country depends on the power industry and its effective economy utilization. Thermal power stations are the most proven reliable sources of electric power. One such power generating industry, "Mettur Thermal Power Station" is located in Mettur dam, Salem District, Tamilnadu. The installed capacity is $(210 x 4) 840 \mathrm{MW}$ which meets nearly $10 \%$ of total grid demands of Tamilnadu.

The power is generated by burning around $130 \mathrm{Tons} / \mathrm{Hr}$. of coal in Boiler with the capacity of 700 Tons/Hour of steam and the steam is admitted in to turbine which spins the turbo generator. This gives the output power of $210 \mathrm{MW}$ in Generator with a terminal voltage of $15.75 \mathrm{KV}$ at 9000 Amps This power is fed in to the grid by stepping up with Generator Transformer at $230 \mathrm{KV}$. Also for the use of its own auxiliaries, the $15.75 \mathrm{KV}$ Generator output is stepped down to $6.6 \mathrm{KV}$ with unit transformers and around $18 \mathrm{MW}$ power is utilized before being fed in to the State Grid.

\section{FUNCTIONING OF THE EXISTING SYSTEM}

The existing system consists of synchronous generator works on the principle of Faraday's law of electromagnetic induction. It states that a coil when placed in a magnetic field will produce an emf. Thus, a generator consists of armature and field winding to do the above mentioned function. The field winding is provided with direct current in order to excite the generator. This excitation is provided by an exciter through slip rings and brushes by means of a DC generator. These are arranged in the same shaft which links the rotor of the synchronous machine.
The power supply of the excitation system [3] will be tapped generator from terminals through a step down transformer and is directly connected to the AVR i.e. the generator power output $15.75 \mathrm{KV}$ is stepped down to $375 \mathrm{~V}$ by excitation transformer and it is directly fed into AVR. The AVR excitation control is to regulate generator voltage and relative power output.

As the terminal voltage varies the excitation control, it maintains the terminal voltage to the required standard and the demand of the reactive power is also met by the excitation control unit. The AVR measures the actual signal with the reference signal and an error voltage called "error signal" is produced is amplified through voltage amplifier. It decides the firing angle of the thyristors which depends upon terminal voltage. Thus the specified voltage is obtained at the alternator output.

Waveforms of generator parameters at $1200 \mathrm{KW}$ load in AVR 


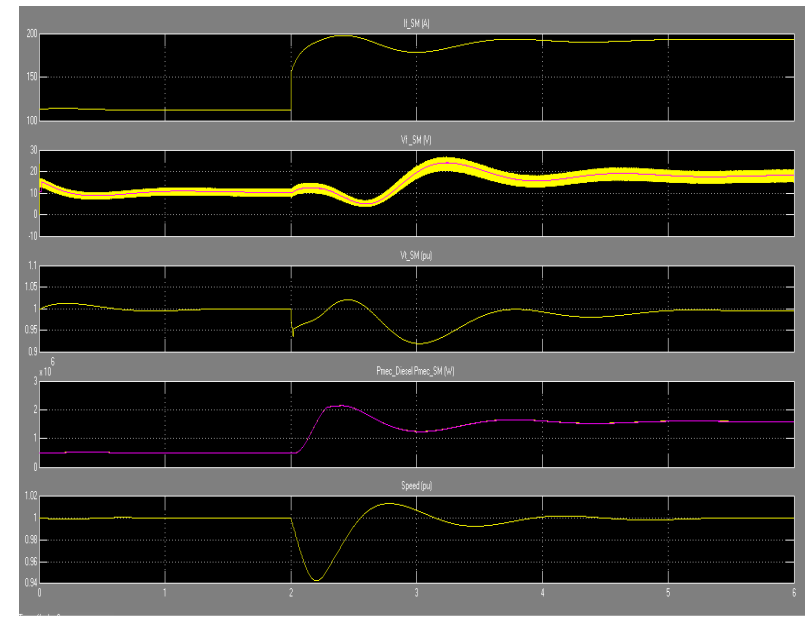

This Graph shows the variations in Field current, Field Voltage, terminal voltage, mechanical input and speed due to changes in Load. It shows that it takes 2.8 seconds to attain stability.

\subsection{Drawbacks of AVR}

1. The voltage correction may not be fast enough for varying loads.

2. The AVR will not respond for the Low voltage damping.

3. It requires regular maintenance

\section{FUNCTIONING OF THE PROPOSED}

\section{SYSTEM}

In the proposed system we are replacing the AVR by ANFIS based Power system stabilizers, so that drawbacks of AVR can be rectified and the ANFIS based PSS provides auxiliary control signals to the exciter to damp the low frequency power system oscillations thereby improving the unit dynamic performance.

\subsection{ANFIS: Adaptive Neuro-Fuzzy Inference}

\section{Systems:}

\subsubsection{Introduction:}

ANFIS is an adaptive network which permits the usage of neural network topology together with fuzzy logic. It not only includes the characteristics of both methods, but also eliminates some disadvantages of their lonely-used case [1].

\subsubsection{Advantages of ANFIS compared with Neuro}

\section{Fuzzy and Neural Network:}

The learning duration of ANFIS is very short than neural network case. It implies that ANFIS reaches to the target faster than neural network. The use of ANFIS instead of neural network would be more useful to overcome faster the complexity of the larger problem.

The aim is to choose the same FIS in both Fuzzy and in ANFIS methods because it combines the advantages of both neural network and fuzzy logic which offers good results.

\subsection{Genetic Algorithm Adaptive Neuro-Fuzzy}

\section{Inference System:}

In this project we use Genetic Algorithm Adaptive NeuroFuzzy Inference System (GA-ANFIS). This method is based on Neuro-fuzzy inference system and genetic algorithm. In GA-ANFIS there are two inputs and one output. In GA-ANFIS there are have five layers.

Layer 1 is the input layer.

Layer 2 is the fuzzification layer.

Layer 3 is the rule layer.

Layer 4 is the normalization layer.

Layer 5 is the defuzification layer.

There are two important difference between GA-ANFIS and ANFIS; firstly, normalization and secondly, adaptation.

\subsubsection{Advantages of GA-ANFIS:}

- No need for system model linearization.

- Consumes less time for computation and has simple design

- $\quad$ Adaptive and robust in nature

- No need to change the actual PSS in the generator as the modifications is made only in the parameters of the existing PSS.

Tests have been conducted for various operating conditions and the results depicts that the proposed PSS with ANFIS provides better power oscillation damping and hence it improves the overall system performance.

\section{OUTPUT WAVEFORMS OF GA-ANFIS PSS}

The Fig (a) shows the variations of Field current, field voltage, terminal voltage, mechanical power and speed respectively due to change in load and it is sensed at small intervals and it is maintained by AVR with GA-ANFIS and the stability is attained very soon than the previous method. It takes about 0.9 seconds to attain stability.

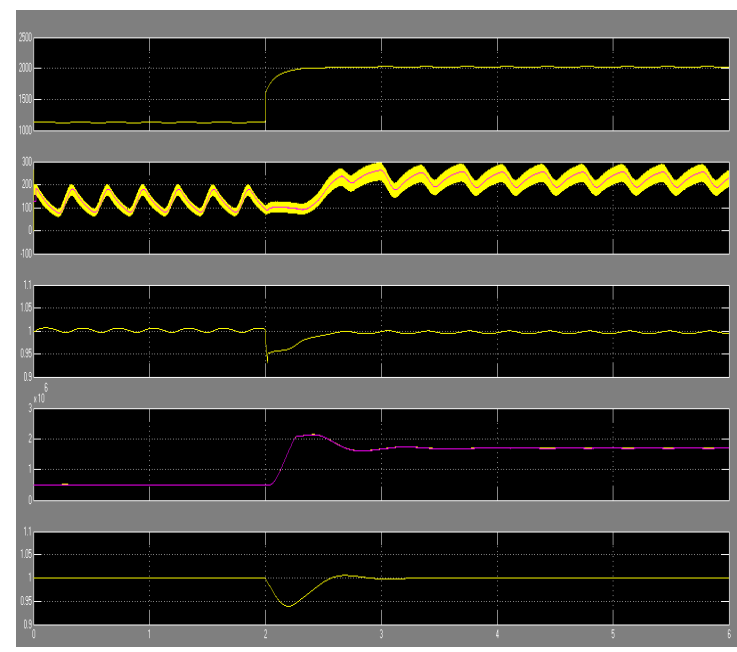

Fig (a): Waveforms of generator parameters at $1200 \mathrm{KW}$ load in GA-ANFIS 


\subsubsection{Conventional PSS Vs. GA-ANFIS PSS}

The Fig (b) shows that AVR with GA ANFIS controller reaches the stability very soon than the AVR with PI controller thereby damping the low frequency oscillations.

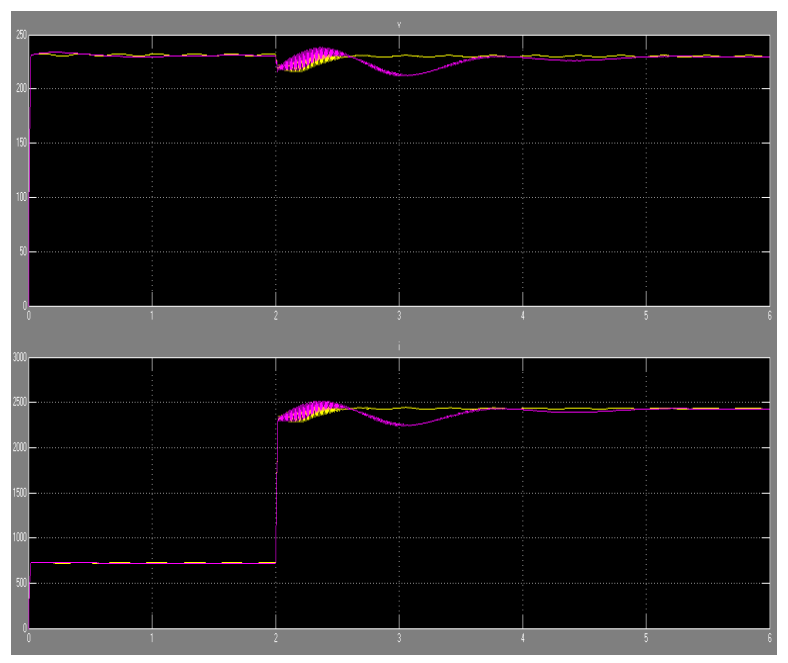

Fig (b): Voltage and current waveforms comparing AVR with GA-ANFIS

In this graph pink colour denotes PI controller and Yellow colour denotes GA ANFIS controller.

\section{CONCLUSIONS}

The proposed method has the features of a simple structure, adaptivity and fast response and also damps the low frequency oscillations than the existing method of voltage control. AVR with PI Controller does not respond to low frequency oscillations and it takes more time to attain stability.

\section{For example:}

If the load change is about $1200 \mathrm{KW}$, the time taken for attaining stability is 2.8 seconds.

AVR with GA-ANFIS controller senses for very small intervals and it damps the low frequency oscillations and within one sec the stability is attained.

\section{For example:}

If the load change is about $1200 \mathrm{KW}$, the time taken for attaining stability is 0.9 seconds

Thus the GA-ANFIS based power system stabilizer is advantageous than existing system.

\section{REFERENCES}

[1]. ANFIS: adaptive -network based fuzzy inference system, IEEE trans system, cybernetics 23(5/6):665-685,

[2]. Genetic Algorithms in Engineering and Computer Science, edited by G.Winter, J.Periaux \& M.Galan, published by JOHN WILEY \& SON Ltd. in 1995
[3]. http://www.scibd.com/46740367/static -excitationsystem

[4]. http://www.electricityguide.info/definition-and-how-itworks-avr-automatic-voltage-regulator.html

\section{BIOGRAPHIES}

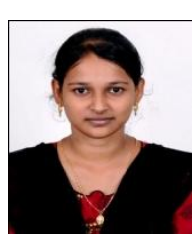

Ms.B.ChristyJuliet was born on $9^{\text {th }}$ December 1991 in Coimbatore. She has completed her UG degree B.E Electrical and Electronics Engineering in SNS College of Engineering during the year 2009 to 2013 under Anna University, Chennai. She is now currently pursuing her PG course specialized in Power Systems Engineering in Kalaignar Karunanidhi Institute of Technology under Anna University Chennai. Her area of interest is power system protection.

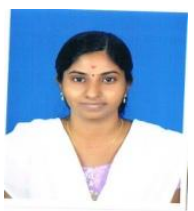

Ms. S.Vidhyashree was born on $16^{\text {th }}$ December 1991 in Coimbatore. She has completed her UG degree B.E Electrical and Electronics Engineering in Karpagam

4 College of Engineering during the year 2009 to 2013 under Anna University, Chennai. She is now currently pursuing her PG course specialized in Power Systems Engineering in Kalaignar Karunanidhi Institute of Technology under Anna University Chennai.

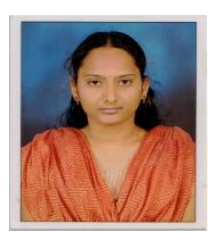

Ms. D.Vinothini was born on $4^{\text {th }}$ June 1991 in Coimbatore. She has completed her UG degree B.E Electrical and Electronics Engineering in Info institute of technology during the year 2009 to 2013 under Anna University, Chennai. She is now currently pursuing her PG course specialized in Power Systems Engineering in Kalaignar Karunanidhi Institute of Technology under Anna University, Chennai. 